\title{
PENETAPAN NILAI KALORI DALAM BATUBARA DENGAN KALORIMETER PARR 6200
}

\author{
Finda Pratiwi Istomo ${ }^{1)^{*}}$, Ameylia Tristiasti ${ }^{2)}$ \\ ${ }^{1)}$ Program Studi Kimia, Universitas Nusa Bangsa \\ JL. K.H. Sholeh Iskandar Km. 4, Cimanggu, Tanah Sareal, Bogor 16166 \\ ${ }^{2)}$ Laboratorium Batubara QARD Indocement Tunggal Prakarsa, Jalan Mayor Oking, \\ Citeureup, Kabupaten Bogor \\ *e-mail: pratiwifinda31@gmail.com
}

\section{ABSTRACT \\ Determining Calory Value of Coal With Calorimeter Parr 6200}

\begin{abstract}
Coal is a source of energy utilized by the process of making cement. This type of coal determines the quality and calorific value of the coal. Determination of calorific value on coal is done by using calorimeter. Coal types studied were $A$ and $B$ coal mixture with ratio 80:20, 70:30, 60:40, and 50:50. The results showed that the mixture of $A$ and $B$ coal with a ratio of 80:20,70:30,60:40, and 50:50 can be used for combustion in the manufacture of cement in the furnace because it has a calorific value above 6000 in accordance with the standards of the cement factory. Water content affects the calorific value of coal, the higher of moisture content, the lower the heating value.
\end{abstract}

Keywords: Coal, Calorimeter, Heat value

ABSTRAK

Batubara merupakan sumber energi yang dimanfaatkan oleh proses pembuatan semen. Jenis batubara menentukan kualitas dan nilai kalor dari batubara tersebut. Penentuan nilai kalor pada batu bara dilakukan dengan menggunakan kalorimeter. Jenis batubara yang diteliti yaitu Campuran batubara A dan B dengan perbandingan 80:20, 70:30, 60:40, dan 50:50. Hasil penelitian menunjukkan bahwa campuran batubara A dan B dengan perbandingan 80:20, 70:30, 60:40, dan 50:50 dapat digunakan untuk pembakaran dalam pembuatan semen di tanur bakar karena memiliki nilai kalori diatas 6000 sesuai dengan standar perusahan pabrik semen. Kadar air mempengaruhi nilai kalori batubara, yaitu semakin tinggi kadar air semakin rendah nilai kalor.

Kata Kunci: Batu Bara, Kalorimeter, nilai kalor

\section{PENDAHULUAN}

Batubara adalah salah satu bahan bakar fosil. Batu bara merupakan batuan sedimen yang dapat terbakar, terbentuk dari endapan organik, terutama dari sisa-sisa tumbuhan dan terbentuk melalui proses pembatubaraan. Pembentukan batubara dimulai sejak periode pembentukan karbon (Carboniferus Period) dikenal sebagai zaman batubara pertama yang berlangsung antara 290 juta sampai 360 juta tahun yang lalu. Oleh karena itu, batubara termasuk dalam kategori bahan bakar fosil (Billah, 2010).

Batubara adalah salah satu sumber energi yang penting bagi dunia. Batubara banyak memainkan peran selama berabadabad, tidak hanya membangkitkan listrik namun juga merupakan bahan bakar utama bagi kegiatan-kegiatan industri seperti industri semen (Rendy et al., 2014). Batubara yang digunakan sebagai bahan bakar diharapkan memiliki nilai kalor yang tinggi untuk mendapatkan efisiensi pembakaran (Lutfy et al., 2013)

Indonesia termasuk negara dengan sumber tambang batu bara terbesar di dunia. Cadangannya diperkirakan 36,3 milyar ton. Jumlah ini sebenarnya cukup untuk memasok kebutuhan energi listrik hingga ratusan tahun ke depan. Sayangnya, Indonesia tidak mungkin membakar habis batu bara dan mengubahnya menjadi energi listrik melalui Pembangkit Listrik Tenaga Uap (PLTU) (Widagdo, 2004).

Salah satu pemanfaatan batubara adalah digunakan sebagai bahan bakar di 
industri-industri, khususnya industri semen. Dalam industri pembuatan semen batubara digunakan sebagai bahan bakar dalam kiln untuk membentuk klinker yang merupakan bahan dasar semen. Secara umum, kegiatan pabrik semen terdiri atas tiga tahap, yaitu penambangan bahan baku, proses produksi semen dan proses pemasaran. Proses produksi secara khusus terdiri dari 4 tahap yaitu penggilingan bahan baku, pembakaran bahan semen, penggilingan akhir dan pengantongan semen. Kegiatan pembakaran dalam proses produksi merupakan proses inti, karena sebagian besar energi diperlukan dalam proses ini (Yakub, 2006).

Jenis batubara menentukan kualitas dan nilai kalor dari batubara tersebut. Nilai kalor dapat di analisis salah satunya dengan menggunakan alat kalorimeter. Kalorimeter adalah suatu metode yang mempelajari jumlah panas/kalor berdasarkan perubahan temperatur. Kalorimeter bom adalah suatu alat yang digunakan untuk menentukan panas yang dibebaskan oleh suatu bahan bakar dan oksigen pada volume tetap. Jenis batubara yang digunakan tergantung dari nilai kalori yang dipakai dalam industri semen tersebut. Dalam Industri khususnya dalam industri semen nilai kalor yang diperbolehkan umumnya mengikuti aturan dari pabrik tersebut (Yakub, 2006).

\section{Bahan dan Alat}

\section{BAHAN DAN METODE}

Bahan yang digunakan yaitu Sampel batubara A, sampel B, sampel batubara campuran $\mathrm{A}$ dan $\mathrm{B}$, larutan $\mathrm{Na}_{2} \mathrm{CO}_{3} 0,07 \mathrm{~N}$, indikator Merah Metil 0,02 \%, air suling. Peralatan yang digunakan yaitu Neraca digital Sartorius, sudip, wadah sampel, kalorimeter bom Parr 6200, Vessel, buret, labu semprot, cawan petri, oven Fisher $105^{0} \mathrm{C}$, desikator.

\section{Metode}

\section{Pencampuran Batubara}

Sampel Batubara dianalisis dengan perbandingan A : B 80:20, 70:30, 60:40, dan 50:50 kemudian di homogenkan.

\section{Penentuan Kadar Air}

Suhu oven dinaikkan sampai $105-110^{\circ} \mathrm{C}$. Cawan petri kosong yang kering dan bersih ditimbang bersama tutupnya sampai ketelitian $0,1 \mathrm{mg}$. Sampel sebanyak $\pm 1,0000$ gram ditimbang sampai terbentuk lapisan, tutup dan timbang lagi sampai ketelitian 0,1 mg. Cawan petri berisi sampel dimasukkan ke dalam oven dengan suhu $105^{\circ} \pm 2$ selama \pm 1 jam. Setelah 1 jam, cawan petri berisi sampel dikeluarkan dari oven dan didinginkan ke dalam desikator. Setelah \pm 15 menit, cawan petri ditimbang.

\section{Penentuan Nilai Kalori}

Kalorimeter BOMB dengan tekanan gas, regulator, volume air pendingin dan aliran listrik dengan kondisi yang baik. Alat dinyalakan dengan menekan tombol hitam yang ada dibelakang alat Aliran gas oksigen dibuka dengan cara memutar pulp hitam ke kiri. Alat di stabilkan tunggu sampai 20 menit. Sampel ditimbang seberat \pm 1.0000 gram ke dalam krusibel. Krusibel ditempatkan pada penyangga elektroda dan atur kawat pemantik tersentuh/kontak dengan sampel. Combustion chamber dengan bomb cap disatukan dengan cara memutar bomb cap ke kanan sampai kencang, dipastikan combustion chamber dan bomb cap sesuai dengan pasangannya. Vessel diisi gas oksigen hingga tekanan maksimum 30 atm (tekan tombol FILL). Vessel dimasukkan ke dalam bomb bucket dan isi dengan 2 liter aquadest dari pipet tank. Elekroda pada terminal nut dimasukan dan pastikan kedua elektroda tersebut terkoneksi dengan terminal nut. Bomb bucket lid dipastikan tertutup rapat, tombol [START] ditekan, kemudian dipilih ID bomb dan dimasukkan berat sampel. Sampai proses analisis selesai dan dicatat hasil analisis. Bomb bucket yang berisi vessel dikeluarkan dari bomb jacket. Gas $\mathrm{CO}_{2}$ dibuang dengan cara memutar knop yang berada di bomb cap. Bagian dalam bomb dibilas dengan air. Semua kawat yang tidak terbakar dari elektroda dibersihkan dan cuci kepala bomb dengan air. Air cucian dititrasi dengan larutan standard $\mathrm{Na}_{2} \mathrm{CO}_{3}$ menggunakan indikator Merah Metil hingga mencapai titik akhir berwarna OrangeMerah. Catat volume penitar. Tombol REPORT ditekan dan dimasukkan nomor contoh. Volume penitar dan Total Sulphur (TS \%ad) dimasukkan. 


\section{Perhitungan}

4.1 Analisis Kadar Air:

$\%$ Kadar Air $=R M=\frac{A-(C-B)}{A} X 100 \%$

Keterangan :

$\mathrm{A}=$ Bobot contoh (gram)

$\mathrm{B}=$ Bobot Cawan kosong (gram)

$\mathrm{C}=$ Bobot Cawan + sampel setelah dikeringkan $105^{\circ}$ (gram)

4.2 Analisis Nilai Kalori:

$$
\mathrm{CV}_{\mathrm{db}}=\frac{C V a d b}{\left(\frac{(1-R M)}{100}\right.}
$$

Keterangan :

$\mathrm{CV}_{\mathrm{db}}=$ Nilai Kalori dalam dry basis (cal/gram)

$\mathrm{CV}_{\mathrm{adb}}=$ Nilai Kalori dalam air dried basis (cal/gram)

$\mathrm{RM}=$ Residual Moisture (Kadar Air)

$(\%)$

Gross Calorivic Value $=$

$$
\frac{(E e X \Delta T)-e 1-e 2-e 3}{A}
$$

Keterangan :

$\mathrm{Ee} \quad=$ Energi Equivalen $\left(\mathrm{cal} /{ }^{\circ} \mathrm{C}\right)$

$\Delta \mathrm{T}=$ perbedan temperatur awal dan akhir $\left({ }^{\circ} \mathrm{C}\right)$

$$
\begin{array}{ll}
\text { e1 } & =\text { Koreksi asam }(\mathrm{cal}) \\
\text { e2 } & =\text { Koreksi Fuse }(\mathrm{cal}) \\
\text { e3 } & =\text { Koreksi sulfur }(\mathrm{cal})
\end{array}
$$

\section{HASIL DAN PEMBAHASAN}

\section{Analisis Kadar Air Batubara}

Hasil analisis kadar air sampel babtubara A dan $\mathrm{B}$ dengan perbandingan 80:20, 70:30, 60:40, dan 50:50 ditunjukkan pada Tabel 1 dan 2. Peningkatan kadar air akan mengurangi suhu pembakaran maksimum dan meningkatkan waktu yang diperlukan untuk pembakaran yang sempurna dalam tungku (Yuliah et al, 2010). Nilai kadar air dari batubara A dan B tergolong berbeda, dikarenakan kedua batubara tersebut dari jenis yang berbeda. Batubara A memiliki kadar air yang tergolong tinggi, sedangkan untuk B memiliki kadar air yang tergolong rendah. Batubara A ini tergolong jenis subbituminus karena memiliki nilai kalor yang rendah dan mengandung banyak air. Batubara B tergolong jenis bituminous karena memiliki nilai kalor yang tinggi serta kandungan airnya yang sedikit. Maka dari itu, dilakukan pencampuran dengan perbandingan 80:20, 70:30, 60:40, dan 50:50 yang hasilnya dapat dilihat dari Tabel 2 .

Tabel 1. Hasil Analisis Kadar Air Batu Bara A dan B

\begin{tabular}{ccc}
\hline No & $\boldsymbol{A}$ & $\boldsymbol{B}$ \\
\cline { 2 - 3 } 1 & $\mathrm{RM}(\%)$ & $\mathrm{RM}(\%)$ \\
2 & 13,14 & 6,53 \\
3 & 13,17 & 6,39 \\
4 & 13,05 & 6,11 \\
5 & 13,02 & 6,26 \\
6 & 13,10 & 6,27 \\
7 & 13,29 & 6,32 \\
8 & 13,22 & 6,48 \\
9 & 13,17 & 6,71 \\
10 & 13,26 & 6,55 \\
$A V G$ & 13,18 & 6,30 \\
\hline$S D$ & 13,16 & 6,39 \\
\hline
\end{tabular}

Keterangan :

RM : Residu Moisture ( Kadar Air) 
Tabel 2. Hasil Analisis Kadar Air Batu Bara Campuran

\begin{tabular}{ccccc}
\hline \multicolumn{5}{c}{ Perbandingan campuran antara batubara A:B } \\
\hline No & $\mathbf{8 0 : 2 0}$ & $\mathbf{7 0 : 3 0}$ & $\mathbf{6 0 : 4 0}$ & $\mathbf{5 0 : 5 0}$ \\
\hline & $\mathrm{RM}$ & $\mathrm{RM}$ & $\mathrm{RM}$ & $\mathrm{RM}$ \\
2 & 11,82 & 11,16 & 10,50 & 9,84 \\
3 & 11,81 & 11,14 & 10,46 & 9,78 \\
4 & 11,66 & 10,97 & 10,27 & 9,58 \\
5 & 11,67 & 10,99 & 10,32 & 9,64 \\
6 & 11,73 & 11,05 & 10,37 & 9,69 \\
7 & 11,90 & 11,20 & 10,50 & 9,81 \\
8 & 11,87 & 11,20 & 10,52 & 9,85 \\
9 & 11,89 & 11,23 & 10,59 & 9,94 \\
10 & 11,92 & 11,25 & 10,58 & 9,91 \\
\hline$A V G$ & 11,80 & 11,12 & 10,43 & 9,74 \\
\hline$S D$ & 11,81 & 11,13 & 10,45 & 9,78 \\
\hline
\end{tabular}

Dari Tabel 2 didapat hasil dari masing-masing perbandingan campuran batubara A dan B tergolong konstan. Gangguan utama kandungan moisture dalam pembakaran ialah terbuangnya sebagian energi untuk menguapkan air tersebut, baik yang terjadi dalam tungku maupun yang terjadi selama penggerusan. Hilangnya energi ini diperkirakan $0,3 \mathrm{MJ} / \mathrm{kg}$ air atau $0,12 \%$ dari nilai kalori untuk setiap penguapan $1 \%$ air. Sebaliknya, adanya sejumlah tertentu air selama pembakaran sangat berguna dalam mengendalikan $\mathrm{NO}_{2}$ dan pembentukan asap (ASTM, 2016). Berdasarkan standar kualitas yang diperbolehkan di Pabrik Semen, batas maksimal nilai kadar air yang diperbolehkan adalah 12\%, sedangkan dari Tabel 2 diketahui bahwa nilai kadar air dari masingmasing perbandingan tersebut masuk dalam kualitas pabrik semen.

\section{Analisis Nilai Kalor Batubara}

Nilai kalor dari batubara A dan B tergolong berbeda. Jika pada nilai kadar air batubara A memiliki kadar air yang tinggi namun memiliki nilai kalor yang rendah di banding batubara B. Begitu juga dengan batubara $\mathrm{B}$ memiliki nilai kalor yang tinggi dan kadar air yang tergolong rendah.

Berdasarkan hasil pada Tabel 4 batubara A : B dengan perbandingan 80:20, 70:30, 60:40, dan 50:50 menunjukan bahwa nilai kalor yang didapat sesuai dengan standar pabrik semen yang telah ditetapkan. Sebagai bahan bakar, batubara dapat dimanfaatkan untuk mengubah air menjadi uap di dalam suatu ketel uap atau boiler PLTU, untuk membakar bahan pembuat klingker di pabrik semen dan sebagai bahan bakar di industri-industri kecil. Pada hakikatnya, semua batubara dapat dibakar, tetapi dalam pemanfaatan sebagai bahan bakar tertentu perlu dipenuhi berbagai persyaratan tertentu pula, misalnya sebagai bahan bakar di PLTU diperlukan batubara yang mempunyai kandungan ash yang lebih kecil dari $30 \%$ (Abdul, 2010). 
Tabel 3. Hasil Analisis Nilai Kalori Batu Bara A dan B

\begin{tabular}{ccc}
\hline No & A & B \\
\hline & HV & HV \\
\cline { 2 - 3 } 2 & 5882 & 7106 \\
3 & 5834 & 7119 \\
4 & 5842 & 7448 \\
5 & 5887 & 7357 \\
6 & 5859 & 7298 \\
7 & 5805 & 7184 \\
8 & 5818 & 7068 \\
9 & 5839 & 7032 \\
10 & 5812 & 7116 \\
\hline AVG & 5844 & 7205 \\
\hline SD & 5836 & 7192 \\
\hline
\end{tabular}

Tabel 4. Hasil Analisis Nilai Kalori Batu Bara Campuran

\begin{tabular}{ccccc}
\hline \multicolumn{5}{c}{ Perbandingan campuran antara batubara A:B } \\
\hline No & $\mathbf{8 0 : 2 0}$ & $\mathbf{7 0 : 3 0}$ & $\mathbf{6 0 : 4 0}$ & $\mathbf{5 0 : 5 0}$ \\
\hline & HV & HV & HV & HV \\
2 & 6079 & 6207 & 6336 & 6464 \\
3 & 6091 & 6220 & 6348 & 6477 \\
4 & 6163 & 6324 & 6484 & 6645 \\
5 & 6181 & 6328 & 6475 & 6622 \\
6 & 6145 & 6291 & 6435 & 6579 \\
7 & 6081 & 6219 & 6357 & 6495 \\
8 & 6068 & 6193 & 6318 & 6443 \\
9 & 6076 & 6194 & 6313 & 6431 \\
10 & 6073 & 6203 & 6334 & 6464 \\
$A V G$ & 6116 & 6252 & 6388 & 6525 \\
\hline$S D$ & 6107 & 6243 & 6379 & 6514 \\
\hline
\end{tabular}

Nilai kalor batubara yang dipergunakan sebagai bahan bakar merupakan komponen utama yang harus dipisahkan. Salah satu komponen yang menentukan harga batubara selain dari nilai kalorinya bisa juga dilihat dari nilai ash, sulphur, HGI, dan partikel halus. Pemilihan batubara dengan nilai kalor yang lebih tinggi akan mengurangi biaya penyediaan fasilitas penerimaan, penanganan, dan penggilingan batubara karena jika nilai batubara sesuai dengan spesifikasi perusahaan tersebut maka pembelian batubara akan berkurang dan juga dapat menghemat biaya produksi juga.
Reaksi dalam kalorimeter bomb berlangsung pada volume dan tekanan tetap. Tekanan yang ada didalam alat sudah diatur tergantung standar dari masing-masing pabrik semen. Dalam hal ini pabrik semen mengacu pada ASTM D5865 yang menggunakan tekanan pada alat bomb sebesar 20-30atm. Kalorimeter bomb merupakan salah satu alat yang digunakan untuk menentukan nilai suatu kalor batubara. Nilai kalori batubara yang telah dianalisis menunjukkan bahhwa campuran batubara A \& B dengan perbandingan 80:20, 70:30, 60:40, dan 50:50 bisa digunakan 
dalam proses pembakaran semen karena memiliki nilai kalor diatas 6000 (ASTM, 2016). bomb :

Reaksi yang terjadi dalam wadah

Batubara $+\mathrm{O}_{2} \rightarrow \mathrm{Abu}+\mathrm{CO}_{2(\mathrm{~g})}+$ $\mathrm{H}_{2} \mathrm{O}_{(\mathrm{g})}+\mathrm{SO}_{3(\mathrm{~g})}+\mathrm{NO}_{2}+$ Kalori

Gangguan utama kandungan moisture dalam pembakaran ialah terbuangnya sebagian energi untuk menguapkan air tersebut, baik yang terjadi dalam tungku maupun yang terjadi selama penggerusan. Hilangnya energi ini diperkirakan $0,3 \mathrm{MJ} / \mathrm{kg}$ air atau $0,12 \%$ dari nilai kalori untuk setiap penguapan $1 \%$ air. Sebaliknya, adanya sejumlah tertentu air selama pembakaran sangat berguna dalam mengendalikan $\mathrm{NO}_{2}$ dan pembentukan asap (ASTM, 2016 ).

Batubara yang digunakan adalah jenis A dan B. Batubara A memiliki nilai kalori yang tergolong rendah, sedangkan untuk batubara B memiliki nilai kalori yang lumayan tinggi. Sehingga akan dihasilkan campuran batubara dengan nilai kalori yang sedang. Pencampuran digunakan sampai perbandingan A : B 50:50, untuk menjaga kadar sulfur yang tinggi, jika kadar sulfur terlalu tinggi akan menyebabkan coating pada proses pembakaran semen. Proses coating adalah proses pengkerakan yang terjadi didalam kiln dimana pada saat pembuatan semen jika suhu pembakaran semen tidak stabil dapat menyebabkan gas buang yang tinggi. Selain proses coating sulfur dengan kadar yang tinggi juga dapat menyebabkan pengkaratan pada dinding kiln.

Penggunaan jenis batubara di dalam plant tergantung atas permintaan dari plant tersebut dan tergantung dari kesanggupan plant mampu atau tidak menerima kandungan dari batubara tersebut. Maka dari itu proses pancampuran batubara dilakukan agar hasil yang didapat bisa mendapatkan hasil yang maksimal.

Selain menetapkan nilai kalori pada berbagai campuran batubara dengan Kalorimeter Bom PARR 6200, dilakukan juga penelitian mengenai hubungan kadar air dengan nilai kalori pada batubara, dan didapatkan grafik seperti pada Gambar 5.

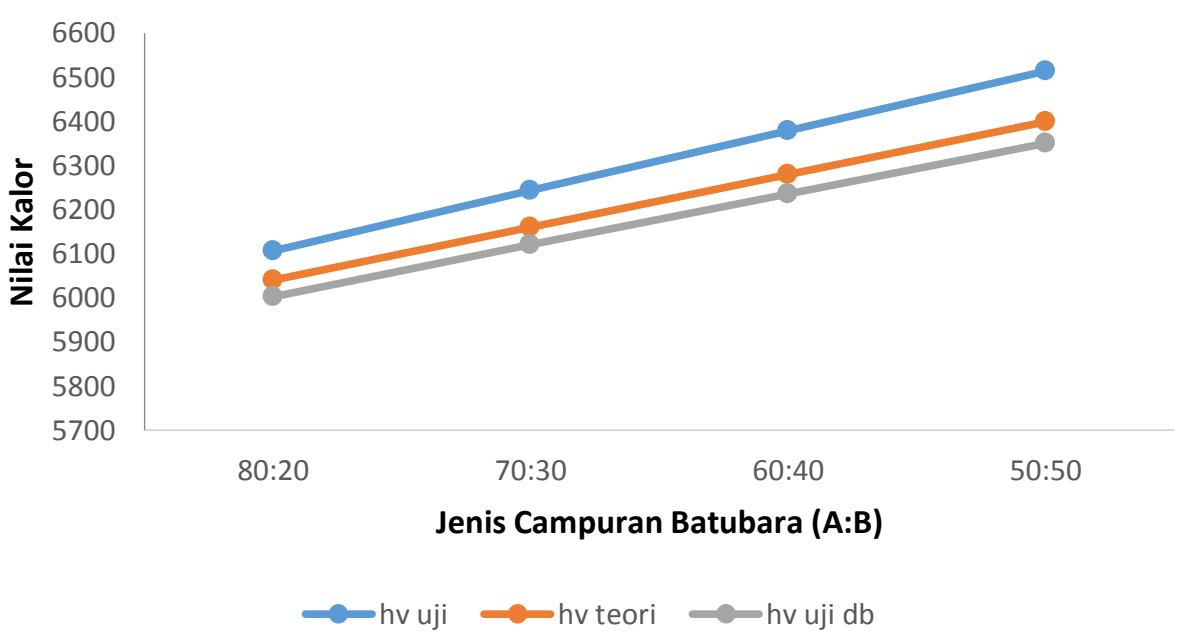

Gambar 1. Nilai kalor campuran batubara A dan B 


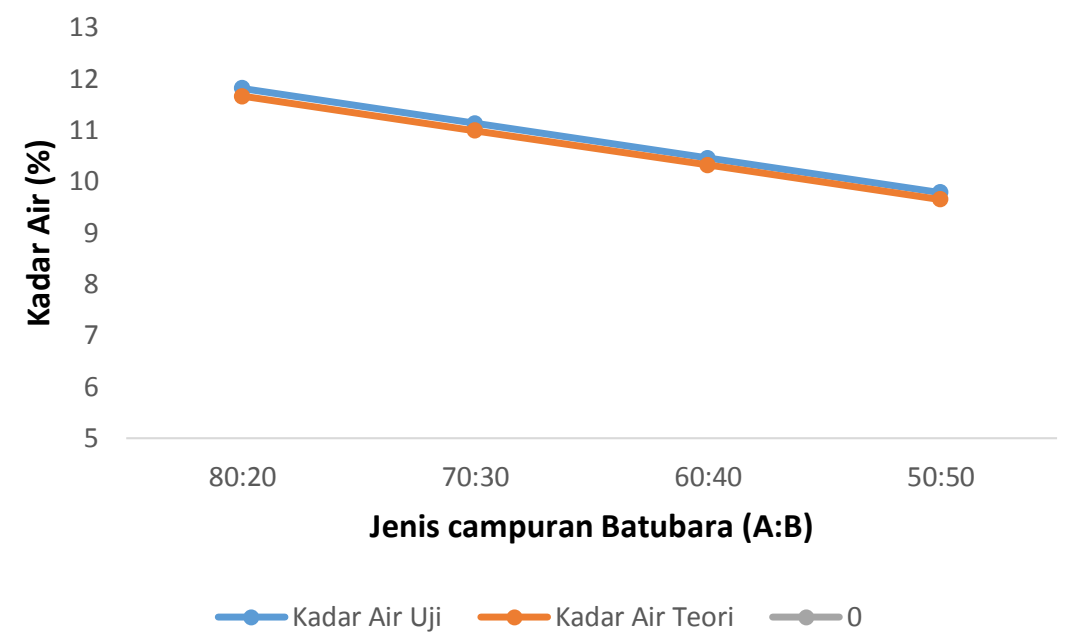

Gambar 2. Kadar air campuran batubara A dan B

Gambar 5 dan 6 menunjukan bahwa semakin rendah kadar air (RM), maka nilai kalori (CV) semakin tinggi. Hal ini terjadi karena pada saat batubara disemprotkan kedalam kiln kandungan air yang ada didalam batubara tersebut menguap untuk mendapatkan kalor dari batubara itu sendiri, sehingga kalor yang dihasilkan menjadi rendah ataupun sebaliknya. Perbandingan perhitungan dengan teori dilakukan untuk memastikan analisis yang sudah dilakukan benar. Kadar air antara teori dan praktik terjadi perbedaan disebabkan batubara pada kondisi halus sangat peka terhadap kelembaban lingkungan, sehingga batubara sangat cepat menyerap air dan melepas air. Oleh karena itu, untuk memastikan analisis yang dilakukan sesuai dengan nilai sebenarnya, maka perlu dilakukan uji monitoring setiap harinya dengan sampel standar batubara. Penyimpanan sampel batubara juga harus diperhatikan karena batubara bersifat higroskopis dan mudah meyerap air dari udara sekitar. Perhitungan dan praktik kita anggap benar dan batubara dianggap sama ketika dihitung dalam kondisi bebas air nilai kalor yang didapat sama (< $46 \mathrm{cal} / \mathrm{g}$ nilai repeatibility untuk satu lab ASTM D 5685).

\section{KESIMPULAN}

Campuran batubara A dan B dengan perbandingan 80:20, 70:30, 60:40, dan 50:50 bisa digunakan untuk pembakaran dalam pembuatan semen di tanur bakar karena memiliki nilai kalori diatas 6000 sesuai dengan standar perusahan pabrik semen. Kadar air mempengaruhi nilai kalori batubara, yaitu semakin tinggi kadar air semakin rendah nilai kalor.

\section{DAFTAR PUSTAKA}

American Standard Test Method. 2011. America Standard D3173-11 Moisture In The Analysis Sampel Of Coal And Coke. ASTM. America.

Benitez, J. 1993. Process Engineering and Design for Air Pollution Control. Prentice-Hall Inc., New Jersey.

Billah, M. 2010. Kemampuan Batubara dalam Menurunkan Kadar Logam $\mathrm{Cr}^{2+}$ dan $\mathrm{Fe}^{2+}$ dalam Limbah Industri Baja. Tekhnk Kimia FTI-UPNV. Jawa Timur.

Day, R. A. Jr. dan A. L. Underwood. 1998. Analisa Kimia Kuantitatif Edisi Keenam. Erlangga. Jakarta.

Direktorat Inventaris Sumber Daya Mineral. 2003. Pengembangan Basis Data 
Sumber Daya Mineral Dan Batubara Indonesia.

Hadi A, Nugroho W, Z Diana F. 2010. Analisis Pengaruh Nilai Kalori Dan Heat Rate (Laju Kalor) Batubara Terhadap Efisiensi Termal PltuEmbalut 2x25 Mw Pt Cahaya Fajar Kaltim. Universitas Mulawarman. Kalimantan Timur.

Harjadi W. 1986. Ilmu Kimia Analitik Dasar. PT Gramedia. Jakarta.

Hendrik, R. 2010. Batubara dan Tambang Batubara. http://bei5000.com/2011/10/15/batubara-dan-tambang-batu-bara/

Indocement. 2018. Profil Perusahaan. http://www.indocement.co.id

Indocement. 2018. Seputar semen. http://www.cement.org/basics/cementi ndustry.asp

Lutfy, A. B, Genta, A., M. Rachmimoellah, dan Romanus, K. T. Nenu. 2013. Pengeringan Low Rank Coal dengan Menggunakan Metode Pemanasan tanpa Kehadiran Oksigen. Institut Teknologi Sepuluh November. Surabaya.

Miller, B. G. 2005. Coal Energy System. Elsevier. United States Of America.

Mustasim, B. 2007. Peningkatan nilai kalor batubara peringkat rendah dengan menggunakan minyak tanah dan minyak residu, Surabaya.

Rendy et al, 2014. Analisis Batubara dalam Penentuan Kualitas Batubara untuk Pembakaran bahan baku semen Di
PT. Indocement Tunggal Prakarsa, Tbk, Bandung

Speight, J. G. 2005. Handbook of Coal Analysis. John Wil and Sons, Inc. New Jersey.

Stach, E., Duncan Murchison, G. H. Taylor, F. Zierke. 1982. Stach's Textbook of Coal Petrology, Gebruder Borntraeger, Berlin.

Sukandarumidi .2006. Batubara Dan Pemanfaatannya. UGM Press. Jogjakarta.

Syarief, R. dan H. Halid. 1993. Teknologi Penyimpanan Pangan. Arcan. Jakarta

Widagdo, S. 2004. Batu bara : Dilema antara Energi Strategis Nasional atau Komoditi. http://turing.freelist .org/archives/geologiugm/012005/msg00133html.

World Coal Institutte. 2011. The Coal Resource A Comprehensive Overview Of Coal. Cambridge House. London

Yakub, A. 2006. Pengambilan, Preparasi Dan Pengujian Contoh Batubara. Laboratorium Batubara. Bandung.

Yuliah Y, Suryaningsih S, Ulfi K. 2010. Penentuan Kadar Air Hilang Dan Volatile Matter Pada Bio-Briket Dari Campuran Arang Sekam Padi Dan Batok Kelapa. Universitas Padjajaran. Bandung.

Yunita, P. 2000. Pembuatan Briket Dari Batubara Kualitas Rendah Dengan Proses Non Karbonisasi Dengan Menambahkan $\mathrm{MgO}$ dan $\mathrm{MgCl}$, UPN"Veteran" Jawa Timur 